\title{
Editorial
}

\section{Management and Organizations in China: Expanding the Frontier of Global Knowledge}

China is a vital arena for contemporary research on organizations and organizational behaviour. At the macro level, it provides an interesting context for studying firms in a period of major economic and corporate transformations. In this context, China's economic and organizational systems differ from those in the other leading economies of the world on many dimensions. Firms remain small by global standards but they employ a work force of about 700 million, larger than that of any other economies on earth. Many markets are fragmented but hypercompetitive for both domestic and global firms. Governmental influence remains pervasive, with nearly a third of the economy remaining state controlled, but with the private sector expecting to soon surpass the state enterprises in production outputs. Participation in MBA and executive education programmes is popular among aspiring managers and companies, but systematic knowledge is lacking on how this distinctive context and its unparalleled rate of change affect organizations.

At the micro level, the Chinese people and their social patterns are fascinating to both scholars and casual observers. One out of every five human beings on the earth is Chinese. The values, conceptions and social patterns of the Chinese people defy any simple characterization, products of both a 5000-year-old cultural tradition and a bold twentieth-century social experiment. Yet as the social sciences have sought to become less culturally bound, there is increasing evidence that fundamental psychological and social patterns differ between Ghina and the West. China, moreover, is an enormous country encompassing myriad ethnic groups, linguistic traditions and religious customs. Analysing the nature and effects of cultural diversity on work and organizations is a ripe topic for research for both psychologists and management scholars. Lastly, a related topic is the Chinese Diaspora, the overseas Chinese whose presence, and their rise and fall in South Asia and other parts of the world, remain a curious phenomenon that capture the imagination of economists, psychologists and sociologists.

Creating a journal where research on firms in China and the people in them is welcomed and nurtured both fulfills a need and creates an opportunity to 
contribute to knowledge on organizations in general and on organizations in China specifically. The need is to chronicle organizations and management systems emerging in a period of profound economic and social change. This is especially important given that Chinese organizations and management systems may not, in the end, resemble their Western counterparts. The opportunity is to reconsider the Western assumptions about organizations and management. There is huge variety in ownership structures, organization forms, business strategies and management practices in China, arguably far greater diversity than that in the West. Diversity not only fuels variations in management practices and employee behaviour and expectations, it also creates entrepreneurial opportunities - both for business people and for scholars seeking to discover and understand forms of organization they have not seen previously. The complexity of China's economy, geography, and legal, social and cultural institutions may force us to rethink fundamental questions about the nature of organizations and their management, including how enterprises adapt to rapidly changing, complex and turbulent environments and how they simultaneously manage relationships with government, compete ferociously at home and develop the capabilities needed to compete globally. Diversity is also evident in the values and expectations of the people, as the contemporary workforce is comprised of those who have experienced the Cultural Revolution as well as those born after that into one-child families and in more affluent conditions. These generational cohorts inevitably create challenges for management and are rich subjects for study.

Both the need and the opportunity for knowledge creation are reflected in the aspirations of management scholars in Greater China (Hong Kong, Taiwan, Chinese mainland) who wish to publish their research in high-quality scholarly journals. Their aspirations are driven, in part, by the requirements of university leaders that their faculty publish their research in international journals. These requirements now exist in Hong Kong, Singapore and Taiwan. Many leading universities in mainland China have already adopted publication in high-quality international journals as the principal criterion for scholarship in the management disciplines. It is to address such aspiration that the Hong Kong University of Science and Technology and Peking University offered generous support to launch Management and Organization Review.

The mission of Management and Organization Review is to publish high-quality original research contributing to knowledge of organizations (a) in general and (b) of special relevance to China. The former includes basic research on management processes and individual behaviour that would serve as the foundation for applied analyses in Chinese firms. It would also include exemplary research in other contexts that can inform theoretical development or innovative methods for research in the Chinese context. The latter includes knowledge that explains or predicts management of companies operating inside and outside of China, and multinational companies operating in China. Both kinds of knowledge, general and 
China-specific, will contribute to the repository of global knowledge on management and organizations.

MOR welcomes research that shows context sensitivity. There are two general types of context-sensitive research, context-embedded and context-specific, each involving a different level of contextualization. Context-embedded research starts with existing models (e.g. bargaining power) and incorporates relevant contextual factors (e.g., party membership or the Chinese form of network, guanxi) in modifying or extending the theoretical predictions on the dependent variables. Contextembedded research extends the boundaries of existing (Western) theories and identifies their contingencies. Context-specific research involves the highest level of contextualization. Researchers may begin with an existing model or constructs, but they try not to be bounded by a priori conceptual frameworks. Context-specific research produces knowledge that is meaningful and valid for the local context and provides the foundation for future comparative and cross-cultural analyses.

In this issue are five papers exemplifying various levels of contextualization. In the first paper James March reports on the evolution of organizational studies in North America and Europe. He observes that there is clear parochialism in that authors of one region tend to cite the work of other authors in the same region and much less frequently cite the work of authors in the other region. However, he considers such parochialism not necessarily a disadvantage to knowledge creation. In fact, he finds parochialism to be desirable for creating valid knowledge. Simple translations of concepts and theories cannot capture the deep cultural meanings. This paper is free of contextualization because its thesis transcends cultural or national boundaries. Interestingly, an indirect message from this paper is to encourage a high level of contextualization in organizational studies by scholars within a region or location. The second paper, by Victor Nee and Yang Cao, is an example of context-specific research involving a high level of contextualization. Using three large samples of employment data in 1994-1995, Nee and Cao identify three market-based institutional processes that reshape the structure of earnings inequality in China's transitional period: the emergence of a highly productive private economy, competition by firms for skilled labour and rising meritocracy in firms' reward systems. The analyses in this study reflect a high level of contextualization in both time and space. The third paper, by Marshall Meyer and Xiaohui Lu, examines the organizational boundary issue in China and observes indefinite boundaries in group corporations and large state-owned enterprises with multiple levels of subsidiaries. Indefinite boundaries create both a challenge and an opportunity to the organization. Meyer and Lu describe how one group corporation effectively managed its boundary with government owners (keeping it at arms length) and its subsidiaries (securing their cooperation through minority shareholding with guaranteed dividend payments). These insights, while specific to Chinese group corporations at this stage of China's development, may have implications for understanding how organizations in general manage their indefi-

C Blackwell Publishing Ltd 2004 
nite boundaries during periods of transformation and change. The fourth paper illustrates the context-embedded research approach. Elke Weber, Daniel Ames and Ann-Renée Blais investigate the effect of decision-makers' culture on their implicit choice of decision-making modes. They compare the decision-making mode of people in China and the United States by content analysing the most popular American and Chinese twentieth-century novels. The results show both similarities and differences in the dynamics of decision mode selection and suggest crosscultural variation in human motivation and decision processes. The last paper in this issue, by Yadong Luo, is similar to the first paper in discussing an issue that transcends national boundaries. Luo proposes an organizational perspective of corruption and discusses four interrelated yet sequential issues that collectively constitute organizational explanations of corruption. He offers a typology of firm's corruption behaviours and elucidates the conditions that may stimulate corruption, how corruption may impede organizational development and a corruption resisting architecture of the firm. This is intended to be a context-free framework that can guide empirical analyses in different contexts.

All five inaugural articles have passed through MOR's review process which is like that of all top-tier journals. Manuscripts are assigned to senior editors, who then request blind reviews from referees who are experts in the substance and methods of research. The decision as to whether to accept a manuscript, request a revision or reject is the senior editor's; it is not a voting process. The editorial process has a developmental bias. When we see manuscripts with potential, we will work with authors to realize this potential. This can be an arduous process and its success in every instance cannot be guaranteed. However, it is, in our judgement, the best way to develop knowledge in a field of inquiry that is fundamentally new.

MOR not only opens a new field of inquiry but also provides a platform for innovations in both theory and methods. We hope you will find MOR to be a source of new knowledge and innovative ways of studying organizations and their management in dynamic contexts; we also hope that you will consider MOR as an outlet for your own scholarly work.

The MOR editorial team

C Blackwell Publishing Ltd 2004. 